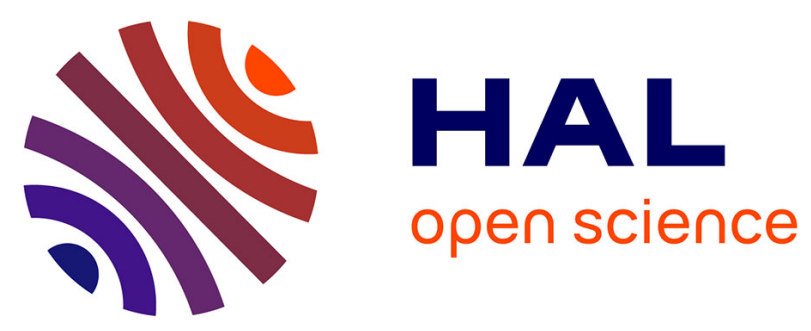

\title{
Effects of an Adaptive Phonological Training Program on Reading and Phonological Processing Skills in Arabic-Speaking Children With Dyslexia
}

Smail Layes, Robert Lalonde, Mohamed Rebai

\section{> To cite this version:}

Smail Layes, Robert Lalonde, Mohamed Rebai. Effects of an Adaptive Phonological Training Program on Reading and Phonological Processing Skills in Arabic-Speaking Children With Dyslexia. Reading and Writing Quarterly, 2019, 35 (2), pp.103-117. 10.1080/10573569.2018.1515049 . hal-03220047

\section{HAL Id: hal-03220047 \\ https://hal.univ-lorraine.fr/hal-03220047}

Submitted on 6 May 2021

HAL is a multi-disciplinary open access archive for the deposit and dissemination of scientific research documents, whether they are published or not. The documents may come from teaching and research institutions in France or abroad, or from public or private research centers.
L'archive ouverte pluridisciplinaire HAL, est destinée au dépôt et à la diffusion de documents scientifiques de niveau recherche, publiés ou non, émanant des établissements d'enseignement et de recherche français ou étrangers, des laboratoires publics ou privés. 
Effects of an adaptive phonological training program on reading and phonological processing skills in Arabic speaking children with dyslexia

Smail LAYES Robert LALONDE $\quad$ Mohamed REBAI

\begin{abstract}
We examined the effects of an adaptive phonological training program on the enhancement of three processing abilities, namely phonological awareness (PA), rapid automatized naming (RAN), and verbal short-term memory (STM) as well as word and pseudo-word reading in Arabic speaking children with dyslexia. An experimental group ( $n=20$; mean age=129.74 months) was compared to an age and reading matched control group $(n=20$; mean age $=126.9$ months) from grades 4 and 5 . The phonological training program focused on the mental representation of phonemes, their identity, and positions in the words. The experimental group outperformed controls in all posttraining measures for reading words and pseudo-words as well as phonological processing components. Findings indicating a strong relationship between phonological processing and reading efficiency are discussed in terms of reading-related skills gained through training.
\end{abstract}

Keywords: developmental dyslexia, adaptive phonological training, phonological processing, phonological awareness, rapid automatized naming, verbal short-term memory. 


\section{Introduction}

Developmental dyslexia is a neurodevelopmental disorder that primarily affects accurate and fluent word reading and spelling (Lyon, Shaywitz, \& Shaywitz, 2003; Peterson \& Pennington, 2012). The main difficulties encountered are related to phonological processing, which refers to the ability to perceive, store, and manipulate speech sounds (Moll et al., 2013). It is widely accepted that the phonological processing deficit is a core contributor to reading disability in Indo-European languages (Lyon et al., 2003; Snowling, 2000; Vellutino, Fletcher, Snowling, \& Scanlon, 2004; Wagner et al., 1997) and Semitic languages such as Arabic (Abu-rabia, Share, Mansour, 2003; Al Mannai, Everatt, 2005; Layes et al., 2014; Saiegh-Haddad, 2011), perhaps a universal hallmark (Goswami, 2000; Ziegler \& Goswami, 2005). Dyslexic children require explicit and intense phonological training to mitigate their deficits (Torgesen et al., 2001). In the present study, we investigated the potential positive effects of adaptive phonological training on reading and phonological processing skills in Arabic-speaking children with dyslexia.

The three main components of phonological processing are phonological awareness (PA), phonological memory, and phonological recoding in lexical access or phonological retrieval, often known as rapid automatized naming (RAN) (Torgesen, Wagner, and Rashotte, 1994; Torgesen et al, 1999; Wagner, Torgesen, Laughon, Simmons, \& Rashotte, 1993). PA includes one's ability to identify and manipulate individual phonemes; RAN includes one's ability to retrieve phonemes rapidly/automatically from long-term memory; phonological memory refers to short-term memory (STM) for phonetically coded material. Among the three constructs, PA is the most powerful construct to predict reading development (Fletcher et al., 1994). Research by Nelson et al. (2012) supports the idea that these skills are best conceived as three separate but correlated abilities rather than highly overlapping measures of one or two underlying constructs.

Impairments occur in phonological representations of the mental lexicon (e.g., Farquharson, Centanni, Franzluebbers, \& Hogan, 2014). According to one theory, a phonological processing deficit is a primal cause of reading difficulties (Stanovich, 1998), manifesting itself in a variety of skills including PA, storage, and retrieval of speech sounds as well as phonological STM. The deficit hinders the learning of letter-sound associations and negatively affects reading development (Ramus, Rosen, Dakin, Day, Castellote, White, Frith, 2003; Goswami, 2013). In support of this hypothesis, robust behavioral evidence shows that dyslexic readers perform poorly on a variety of phonological tasks requiring verbal STM (e.g. digit span), PA (e.g. phoneme deletion and blending), and phonological decoding (e.g. pseudo-word reading) (Wagner, Torgesen, \& Rashotte, 1994; Ramus et al., 2003). Inadequate PA has been suggested to be one of the most reliable 
diagnostic indicators of reading disabilities (Goswami, 2002; Torgesen \& Mathes, 2002; Snowling, 2000). Similar to other languages, a PA contribution to reading development was also documented in Arabic (Abu-Rabia and Abu-Rahmoun, 2012; Asaad and Eviatar, 2014; Saiegh-Haddad, 2011).

Phonological recoding in lexical access, commonly labelled RAN, is the time taken to process familiar verbal information (e.g. objects, letters, colors and digits), which requires rapid retrieval of phonological forms (names) of items (Wolf \& Bowers, 1999). RAN has been shown to be a strong predictor of reading ability and a significant symptom of reading difficulty across languages (Di Filippo et al., 2005; Ding, Richman, Yang, \& Guo, 2010; Furnes, Samuelsson, 2011; Georgiou, Parrila, \& Kirby, 2006). Consequently, PA and RAN have gained importance in understanding poor reading as well as guiding programs aimed at remediation of reading difficulties (e.g. Kirby, Parrila \& Pfeiffer, 2003; Powell, Stainthorp, Stuart, Garwood \& Quinlan, 2007; Wolf \& Bowers, 1999).

Phonological STM is a component of working memory used to store verbal information for a small amount of time (Baddeley, 1986; Baddeley \& Wilson, 1993). Studies across languages have reported limitations in verbal memory skills in children with reading disabilities (Griffiths \& Snowling, 2002; Seigneuric, Ehrlich, Oakhill, \& Yuill, 2000). Because phonological memory is dependent on the activation of phonological codes, children with reading disabilities perform poorly on memory span tasks (Kibby \& Cohen, 2008). It has been claimed that a defective phonological memory may result from poorly specified phonological representations and the phonological features of sounds (Long \& Jacewicz, 2016).

Several Arabic-based studies have underscored the role of phonological processing. AbuRabia, Share \& Mansour (2003) noted that, consistent with their monolingual English-speaking counterparts, dyslexic Arabic readers showed poor phonological decoding abilities and PA in comparison to age-matched typical readers and younger reading-matched readers. More recently, consistent findings with Abu-Rabia and colleagues (Abu-Rabia, 2003; Abu-Rabia \& Siegel, 2003) were reported by Layes et al (2015b), who demonstrated that the most marked differences between typical and dyslexic readers were evident in PA and RAN explained mainly through differences in language sound structure. However, descriptive studies may simply show correlational evidences between phonological processing and reading rather than providing evidence in favor of a causal link between them. Hence, the strongest argument in support of a role of phonological processing in reading acquisition comes from training studies (Castles and Coltheart, 2004) concerning the impact of PA on reading (Torgesen et al., 2001; Wise, Ring, \& Olson, 1999).

Although many studies have investigated the impact of training programs on PA and reading competence (Blachman et al., 2004), little is known about the effect on RAN and phonological STM. Only a small number have investigated generalization training effects of PA, RAN, or STM 
(Schneider, Küspert, Roth, Vise, \& Marx, 1997; van Kleeck, Gillam, \& Hoffman, 2006). Schneider et al. (1997) examined whether PA training generalizes to other phonological processing skills such as verbal working memory in a cohort of normally developing children. The training of German kindergarten children on a set of PA skills for six months improved scores on PA, reading, and spelling at the end of the first and second grade; however, no improvement was found on a word span task.

Although a phonological processing deficit is a main manifestation of developmental dyslexia across scripts, the relative contribution of phonological processing skills to reading development is greatly affected by the regularity of grapheme-phoneme correspondence (e.g. Goswami, 2000; Ziegler \& Goswami, 2005). This issue may represent an important area for investigation to provide a causal relation between phonological processing and word reading, particularly in shallow orthographies that greatly rely on phonological processing such as Arabic (Abdelhadi, Ibrahim, Eviatar, 2011). While Arabic letters represent consonants, vowels occur in print as a set of diacritical marks which facilitate reading accuracy. In un-vowelized Arabic, all diacritical marks are absent and vowel identity must be restored as an integral part of word identification (Ibrahim, 2013). Beginners need to read diacritic signs before developing a lexical strategy relying less and less on the diacritic system after three years of schooling.

In a previous study (Layes et al., 2015b), a phonological training program was effective in promoting gains in PA, word reading, and RAN in Arabic children with dyslexia. It was suggested that more phonological processing skills could provide further evidence for the effectiveness of phonological training. The present study includes phonological STM in addition to PA and RAN as key components in phonological processing. We hypothesized that phonological training enhances PA and improves RAN and verbal STM as well as word reading and pseudo-word decoding.

\section{Method}

\section{Participants}

Participants were initially recruited as poor readers $(n=87)$ by teachers and then by poor performances on word and pseudo-word reading. After eliminating two cases whose profiles did not match with exclusive criteria detailed bellow, we included forty children diagnosed with dyslexia on the basis of at least one standard deviation below their age (Berninger et al., 2008). Participants were then equally divided into two groups following a randomized design in which children were assigned to each condition individually, an experimental group $(n=20)$ with a mean age of 122.9 months $(\mathrm{SD}=11.40)$ and a control group $(\mathrm{n}=20)$ aged 124.65 months $(\mathrm{SD}=10.08)$.

All participants were native Arabic speakers exposed to Standard Arabic in regular classes and exempt from any oral language disability based on teacher reports. Children were excluded if they had a history of hearing or visual impairment, had below average scores on Raven Standard 
Matrices, repeated a school grade level, and had a developmental disorder such as hyperactivity. Independent t-tests showed no difference between the two groups on age and Raven scores (Table $1)$.

\section{Design and Procedure}

Before being trained or not, all participants were tested individually on criterion-referenced reading tests after consent by parents informed about the general aim of the study. The phonological program involved face-to-face interactive training carried out in a quiet room inside a school building but outside regular classroom hours over a period of 12 weeks, 3 sessions per week, each training session lasting approximately $40 \mathrm{~min}$. The duration and frequency of training sessions seemed to be relevant to the age group (Griffiths \& Stuart, 2011). As in most phonological training programs, we used an adaptive training procedure that gradually adjusts task difficulty with individual performance. If an individual had more than $70 \%$ correct, we increased the number of items in the task.

\section{Measures}

\section{Pre and Post training measures}

\section{Non-verbal IQ Test}

The Raven Standard Progressive Matrices is a non-verbal test of reasoning ability and general intelligence. We used the shortened form (Bouma et al., 1996) comprising 36 items (Sets A, $\mathrm{B}$, and C) consisting of a target matrix with one missing part. The children selected from six to eight alternatives to fill the missing patch.

\section{Word and pseudo-word reading tasks}

A list of eighty words $(\alpha=.82)$ was given and read aloud (40 frequent words and 40 infrequent words). The words varied in length (disyllabic and trisyllabic) and frequency (high and low). In addition, 40 pseudo-words $(\alpha=.90)$ controlled for orthographic length were used (Layes, et al., 2014; Layes et al., 2015a, b).

Phonological awareness: The phoneme blending task (test-retest reliability, $r=.48$ )

Phoneme blending is described as the ability to connect phonemes in spoken language (Perez, 2008). Phoneme blending was highly correlated with future reading success primarily because of the importance of decoding (Adams, 1990; Perez, 2008). When a child encounters an unfamiliar word in print, his ability to identify and blend the phonemes that correspond with each letter or letter combination helps him successfully read the word and increases the probability he or she will recognize the word the next time. Twenty pairs of words were presented orally and participants isolated the initial syllables from each word to pronounce the new combination. Words included clusters of consonants (CVCVC), since Arabic words are trilateral.

Rapid Automatized Naming task: RAN objects (test-retest reliability, $r=.51$ ) 
The RAN task, used to assess the speed of processing in naming objects (Wolf \& Bowers, 1999), was elaborated in a previous study and highly related with reading in Arabic-speaking children (Layes et al., 2015). Prior to timed naming, each participant was asked to name the stimuli in a practice trial to ensure familiarity. Participants then named as quickly as possible recurring objects (scissors, cat, book, pen, and hand) arranged semi-randomly in eight rows and repeated 10 times. The time needed to name all the stimuli was measured.

Phonological STM test (test-retest reliability, $r=.53$ )

We opted for the pseudo-words span test because of its attested validity in assessing phonological STM capacity (Baddeley, 2003; Gathercole, 2006). It comprised 24 pseudo-words varying in length. The items were presented one by one according to their length from 3 to 6 syllables, composed of six items for each length, in which participants repeated pseudo-words as accurately as possible with no time constraint. The pseudo-words were presented in a specific order, and participants must repeat them one by one.

\section{The phonological training program: Background and content}

Based on a previous phonological training study for Arabic-speaking children (Layes et al., $2015 b$ ), this program was designed as an explicit interactive training focusing on phoneme manipulation and involving a multitude of activities that aid children in identifying beginning, middle, and end phonemes as well as blending, segmenting, and deleting sounds in spoken words (Joseph, 2007) as highly inter-correlated sub-skills. Particular consideration was given to phonological representation as a basic skill in word recognition. Unlike the previous program, it did not explicitly comprise letter sound correspondence.

The central goal is to improve the performance of phonological processing with direct implication of verbal memory as two intertwined skills underlying the reading process. The tasks involved the mental segmentation of words, the identification of the same initial and final phonemes in different words based on their graphical illustrations (images), and the detection of similarity/dissimilarity in sequences of phonemes. The training took place in small group settings with an average of seven children and was conducted by one of the researchers and two assistants. Assistant trainers attended each training session provided by the researcher to ensure training quality including time control, content delivery, and material presentations.

The main sub-skills targeted over the course of the sessions were: 1 - The phonological representation (word and phoneme) via recognition and identification of phonemes and word position:

- Identification of phonemes composing the word

- Identification of images based on the shared phonemic construction

- Identification of images via phonemes in different positions in the word 
2 - Phoneme manipulation:

- Blending phonemes extracted from given words

- Phoneme deletion from different positions in the word

3- Auditory discrimination of phonemes (auditory verbal information processing and memory)

- Auditory identification of the similarity between strings of phonemes

- Auditory identification of the similarity between pseudo homophones. Ex [ بنات نبات nabatbanat ] (plant-girls)

4- Visual discrimination of letters: (visual verbal information processing and memory)

- Visual identification of the similarity between strings of letters

- Visual identification of the similarity between pseudo homographs [ نحلة نخلة nakhla-nahla] (bee-palm)

Since PA requires oral presentations, children were instructed with the aid of the trainer to pronounce the word indicating the name of each image (object) before executing the task.

\section{Results}

\section{Baseline assessment}

With regard to inclusion criteria, comparison between training and control groups are presented in Table (1), including scores for reading and phonological tasks, showing similar performances at baseline assessment, as well as those for age and Raven scores.

\section{Insert table 1}

\section{Training Effects}

Post-training comparisons between the two groups shown in Table (2) revealed intergroup differences on all reading and phonological processing tasks except RAN. Children with dyslexia taking phonological training also had higher total scores while reading words and pseudo-words (M $=43.35, \mathrm{SD}=4.56)$ than did controls $[(\mathrm{M}=33.75, \mathrm{SD}=2.63), \mathrm{t}(2.02)=8.14, \mathrm{p}<.000]$.

\section{Insert table 2}

To examine further the potential effects of the phonological training program, we compared pre- versus post-training periods for each group separately with the paired t-test for dependent samples (Table 3). Results for the experimental group indicate significant improvements for posttraining measures over pre-training measures except RAN. On the contrary, results show nonsignificant differences between the two assessment periods for the control group (Table 4).

\section{Insert table 3}

A one-way multivariate analysis of covariance (MANCOVA) controlling for pre-training measures was conducted on reading and phonological processing scores. For the total reading score and phonological processing tasks, the analysis output revealed an omnibus group factor effect [F 
$(6,29)=14.18, p=0.000$, Pillai's trace $=.746 ;$ partial $\left.\eta^{2}=.746\right]$, indicating significant differences between the pre- and post-training periods in the training group.

\section{Insert table 4}

Follow-up univariate analyses (ANOVAs) show significant differences based on group factor in frequent word $\left[\mathrm{F}(1,34)=28.07, \mathrm{p}<.000\right.$, partial $\left.\eta^{2}=.45\right]$, infrequent word $[\mathrm{F}(1,34)=$ $38.58, \mathrm{p}<.000$, partial $\left.\eta^{2}=.53\right]$, pseudo-word $\left[\mathrm{F}(1,34)=5.97, \mathrm{p}<.02\right.$, partial $\left.\eta^{2}=.15\right]$, PA $\left[\mathrm{F}(1,34)=8.28, \mathrm{p}<.007\right.$, partial $\left.\eta^{2}=.20\right]$, verbal STM $\left[\mathrm{F}(1,34)=14.09, \mathrm{p}<.001, \eta^{2}=.30\right]$, and $\operatorname{RAN}\left[\mathrm{F}(1,34)=12.26, \mathrm{p}<.001\right.$, partial $\left.\eta^{2}=.25\right]$.

\section{Insert Figure 1}

\section{Discussion}

The aim of the current study was to investigate the effects of a phonological training program on word and pseudo-word reading efficiency as well as on PA, verbal STM, and RAN in Arabic speaking children with dyslexia. Positive effects of the program replicate previous findings in an Arabic speaking cohort with dyslexia (Layes et al, 2015b). More specifically, our findings demonstrate that phonological training results in gains in each of the three phonological processing components. These results are consistent with previous meta-analyses of phonological training (Bus \& Van IJzendoorn, 1999), suggesting that phonological training increases speech sound awareness and ameliorates reading achievement. Findings support the notion that phonological processing is a core contributor to reading ability regardless of orthography (Kibby, Lee, Dyer, 2014).

\section{Effects of phonological training on phonological processing}

The children with dyslexia receiving phonological intervention outperformed age and reading matched controls on all phonological measures after MANCOVA and univariate analyses. These results lead us to infer that phonological intervention improves not only PA typically observed in children with reading disability but also retrieval of the phonological code (RAN) and verbal STM. The persistent defect of phonological processing on the $4^{\text {th }}$ and $5^{\text {th }}$ grade cohort may indicate that learning to read in Arabic is challenged by the transition from the vowelled script (transparent) to a less transparent form when children learn unvowelized words. This transition may make more complicated the process of establishing precise phonological representations in readingdisabled children, hindering grapheme to phoneme conversion. The most potent effect occurred for PA assessed by the blending phoneme test, as in previous investigations (Fälth, Idor, \& Tomas, 2011; Lyster, 2002; Snowling \& Hulme, 2011; Torgeson, 2006), including Arabic (DallashehKhatib et al, 2014), demonstrating that awareness of word structure is related to reading acquisition across languages. This finding provides additional evidence that phonological intervention may 
apply qualitative changes on the underlying phonological representations which, in turn, make phonological processing processes more efficient.

Phonological intervention was also effective regarding RAN, indicating that RAN taps into basic skills involved in phonological and reading processes (Plaza \& Cohen, 2003). This agrees with data published by Wang (2017), who found significant improvements after PA training on rapid digit naming of Chinese. The phonological training program concerns the exclusive use of images rather than audition, which seems to have a positive impact on retrieval speed of verbal representations.

A major debate concerns whether impaired rapid naming and phonological processing deficits in dyslexics are independent factors or not. The positive impact of phonological intervention on PA and RAN favors the theoretical position that naming speed deficits reflect inefficient phonological recoding in lexical access (Wagner \& Torgesen, 1987) as a natural consequence of poor phonological representations (Snowling, 2000). Therefore, RAN should be part of the phonological processing construct along with PA and phonological memory (Araújo, Faísca; Petersson, Reis, 2011). The present findings support the view that the slower speed in naming tasks found in dyslexic subjects is caused by difficulties in retrieving phonological representations for matching to a visual symbol (Torgesen et al., 1997; Wagner, Torgesen, \& Rashotte 1994).

The present study also revealed a significant impact of the phonological intervention program on verbal STM. We cannot exclude a positive impact of the phonological similarity decision task involved in the program, based on the activation of short-term retention of phonemic sequences until the decision on phonemic structure similarity is made. These findings indicate that impaired verbal STM may reflect poor phonological representations in memory and inadequate recall of phonological items leading to inaccurate application of grapheme-phoneme correspondences (Thomson, Richardson and Goswami, 2005). Wagner et al. (1997) argued that efficient phonological encoding enables the beginning reader to maintain an accurate representation of phonemes associated with letters or parts of words. The phonological encoding and retrieval deficits are thought to be underlying sources of reading difficulties in subjects with dyslexia because speech sounds are poorly represented, stored, or retrieved, and consequently learning grapheme-phoneme correspondences will be affected (Vellutino \& Fletcher, 2007). Majerus and Cowan (2016) stated that if linguistic representations are poorly developed, verbal STM will be directly affected. In the case of dyslexia, the verbal STM impairment could be a consequence of the phonological processing impairment. This finding may partially, at least, support the conception stipulating that deficits in phonological memory and PA stem from a common source, namely deficiencies in the quality of phonological representations (Torgesen et al., 1994; Wagner, 
Torgesen, \& Rashotte, 1994). Therefore, phonological STM may be important in the acquisition of letter-phoneme correspondences by the storage of phonological information which involves creating a sound-based representation of written words in memory (Brunswick, Neil Martin and Rippon, 2012). The current evidence suggests that although verbal STM improves, its role as part of the phonological processing construct cannot be the cause of reading abilities (Wagner et al. 1997).

\section{The effects of phonological training on decoding words and pseudo-words}

By the end of the training program, participants in the experimental group performed better in reading words and pseudo-words, suggesting that it helped participants in identifying the internal phonological structure of words leading to more precise mapping of sounds to letters and targeting the awareness of individual sounds (phonemes) in word composition (Ehri, Nunes, Stahl, et al., 2001). In agreement with previous studies, our results show that improvements in PA lead to improved reading skills (Høien-Tengesdal \& Tønnessen, 2011; Nithart, Demont, Metz-Lutz, Majerus, Poncelet, \& Leybaert, 2011), improving the ability of sounding out words in struggling readers (Roman, Kirby, Parrila, Wade-Woolley, \& Deacon, 2009). Similar findings were reported in another Arabic-based study (Makhoul, Olshtain, Ibrahim, 2015) examining the potential impact of phonological skills on reading acquisition and prevention of reading failure in second grade atlinguistic risk readers. Our findings agree with research demonstrating the influence of PA on reading ability up to at least the fourth grade (Catts et al., 2005; Wagner et al., 1997). The amount of PA a child possesses affects reading development such that exposure to phonological instruction can impact reading growth (Hatcher et al., 2006; Wagner et al., 1994).

In support of the phonological deficit hypothesis stating that the reading disorder is caused by a specific deficit in phonological processing (Vellutino \& Scanlon, 1987; Ramus et al., 2003), our dyslexic subjects who performed poorly on PA, pseudo-word decoding, and phonological retrieval benefit from phonological training focusing on phoneme representation, which may generalize to phonological processing skills, providing support of a causal link between PA and reading acquisition (Hulme, Snowling, Caravolas and Carroll, 2005; Wagner, Torgesen, \& Rashotte, 1994). It is likely that phonological processing limitations hinders children with reading difficulties to develop fully specified phonological and orthographic representations of words (Goswami, 2002).

\section{Conclusions}

Our findings add evidence to studies in several languages concerning the impact of phonological training on reading proficiency, addressing several sub-skills at phonologic and phonemic levels, pointing to the contribution of phonological training in facilitating the development of phonological processing abilities in children with reading disabilities (e.g. Høien- 
Tengesdal \& Tønnessen, 2011; Schneider et al., 1997). These findings support the view that dyslexia is caused by a phonological processing deficit and emphasize the importance of establishing phonological representations of words and phonemes in reading Arabic (Asaad and Eviatar, 2014; Saiegh-Haddad (2004, 2005). Our findings have practical implications for instructional methods applied in learning to read: better understanding of PA, RAN, and verbal STM may help in basic reading skills, supporting early screening of phonological processing as a way to identify children at risk (Wagner et al. 1997).

Theoretical implications could also be drawn about whether PA, RAN, and verbal STM reflect separate but correlated abilities (e.g. Nelson et al., 2012) or overlap on one underlying construct (e.g. Wagner et al., 1993). Our findings are consistent with the latter position in that all three measures improved in the experimental group. However, we cannot rule out motivational gains or other factors potentially confounding treatment effects. Future studies should incorporate in the experimental design active control groups unrelated to phonological training (von Bastian, Oberauer, 2014). Long-term monitoring is necessary to demonstrate maintenance effects by conducting follow-up assessment. A long-term phonological training study is needed to examine more deeply the bidirectional relation between PA and reading acquisition (e.g. Castles \& Coltheart, 2004).

\section{References}

Abdulhadi S, Ibrahim R, Eviatar Z. Perceptual load in the reading of Arabic: Effects of orthographic visual complexity on detection. Writing Systems Research. 2011;3(2):117-127. doi: $10.1093 / \mathrm{wsr} / \mathrm{wsr} 014$.

Abu-Rabia, S., \& Abu-Rahmoun, N. (2012). The role of phonology and morphology in the development of basic reading skills of dyslexic and normal native Arabic readers. Creative Education, 3(07), 1259.

Abu-Rabia, S., \& Siegel, L. (2003). Reading skills in three orthogra-phies: The case of trilingual Arabic-Hebrew-English-speaking Ara-bic children. Reading and Writing: An

Interdisciplinary Journal, 16, 611-634. doi:10.1023/A:1025838029204

Abu-Rabia, S., Share, D. \& Mansour, M.S. (2003) Word recognition and basic cognitive processes among reading-disabled and normal readers in Arabic. Reading and Writing 16: 423. https://doi.org/10.1023/A:1024237415143

Al Mannai, H., \& Everatt, J. (2005). Phonological processing skills as predictors of literacy amongst Arabic speaking Bahraini children. Dyslexia, 11(4), 269-291.

Asaad, H., \& Eviatar, Z. (2014). Learning to read in Arabic: The long and winding road. Reading and Writing, 27(4), 649-664.

Baddeley A. (2003) Working memory and language: an overview. J Commun Disord.,36 (3),189208.

Baddeley A \& Wilson Barbara, A. (1993). A developmental deficit in short-term phonological memory: Implications for language and reading. Memory 1, (1),

Blachman BA, Schatschneider C, Fletcher JM, Francis DJ, Clonan S, Shaywitz B, et al. (2004) Effects of intensive reading remediation for second and third graders. Journal of Educational Psychology:;96:444-461. 
Brunswick, N., Martin, G. N., \& Rippon, G. (2012). Early cognitive profiles of emergent readers: a longitudinal study. Journal of Experimental Child Psychology, 111(2), 268-285. DOI: 10.1016/j.jecp.2011.08.001

Bus, A \& van IJzendoorn, M. (1999). Phonological Awareness and Early Reading: A MetaAnalysis of Experimental Training Studies. Journal of Educational Psychology, 91, 403 414 10.1037//0022-0663.91.3.403.

Castles, A \& Coltheart, M (2004). Is there a causal link from phonological awareness to success in learning to read?. Cognition. 91.77-111

Catts HW, Adlof SM, Hogan TP, Weismer SE. (2005). Are specific language impairment and dyslexia distinct disorders? J Speech Lang Hear Res. 48:1378-96.

Dallasheh-Khatib, R., Ibrahim, R., \& Karni, A. (2014). Longitudinal data on the relations of morphological and phonological training to reading acquisition in first grade: the case of Arabic language. Psychology, 5(8), 918-940.

Di Filippo, G., Brizzolara, D., Chilosi, A., De Luca, M., Judica, A., Pecini, C., et al. (2005). Rapid naming, not cancellation speed or articulation rate, predicts reading in an orthographically regular language (Italian). Child Neuropsychology, 11, 349-361.

Ding, Y., Richman, L. C., Yang, L.-Y., \& Guo, J.-P. (2010). Rapid automatized naming and immediate memory functions in Chinese Mandarin-speaking elementary readers. Journal of Learning Disabilities, 43, 48-61.

Ehri, L. C., Nunes, S. R., Stahl, S. A., \& Willows, D. M. (2001). Systematic phonics instruction helps students learn to read: Evidence from the National Reading Panel's meta-analysis. Review of Educational Research, 71(3), 393-447. http://dx.doi.org/10.3102/00346543071003393

Farquharson, K., Centanni, T. M., Franzluebbers, C. E., \& Hogan, T. P. (2014). Phonological and lexical influences on phonological awareness in children with specific language impairment and dyslexia. Frontiers in Psychology, 5, 838. http://doi.org/10.3389/fpsyg.2014.00838

Fletcher, J. M., Shaywitz, S. E., Shankweiler, D., Katz, L., Liberman, 1., Stuebing, K., Francis, D. J., Fowler, A., \& Shaywitz, B. A. (1994). Cognitive profiles of reading disability: Comparisons of discrepancy and low achievement definitions. Journal of Educational Psychology, 86, 6-23

Furnes B, Samuelsson S. (2011) Phonological awareness and rapid automatized naming predicting early development in reading e spelling: Results from a cross-linguistic longitudinal study. Learn Individ Differ.;21(2):85-95.

Gathercole S. E. (2006) Non-word repetition and word learning: the nature of the relationship. Appl. Psycholinguist. 27, 513-543

Georgiou, G. K., Parrila, R., \& Kirby, J. R. (2006). Rapid naming speed components and early reading acquisition. Scientific Studies of Reading, 10, 199-220.

Goswami U (2013), "Dyslexia - in tune but out of time." Psychologist 26(2): 106-109

Goswami, U. (2000). Phonological representations, reading development and dyslexia: Towards a cross-linguistic theoretical framework. Dyslexia (Chichester, England), 6(2), 133-151.

Goswami, U. (2002). Phonology, reading development and dyslexia: A cross-linguistic perspective. Annals of Dyslexia, 52, 1-23.

Griffiths, Y \& Stuart, M. (2011). Reviewing evidence-based practice for pupils with dyslexia and literacy difficulties Journal of Research in Reading Journal of Research in Reading, 36, 1, 1467-9817 doi.org/10.1111/j.1467-9817.2011.01495.x

Griffiths, Y.M., \& Snowling, M.J. (2002). Predictors of exception word and nonword reading in dyslexic children: The severity hypothesis. Journal of Educational Psychology, 94, 34-43.

Hatcher PJ1, Goetz K, Snowling MJ, Hulme C, Gibbs S, Smith G. (2006) Evidence for the effectiveness of the Early Literacy Support programme. Br J Educ Psychol. Jun;76 (Pt 2):351-67. 
Høien-Tengesdal I., Tønnessen F.-E. (2011). The relationship between phonological skills and word decoding. Scandinavian Journal of Psychology, 52, 93-103. doi:10.1111/j.14679450.2010.00856.x

Hulme C., Snowling M., Caravolas M., Carroll J. (2005). Phonological skills are (probably) one cause of success in learning to read: A comment on Castles and Coltheart. Scientific Studies of Reading, 9, 351-365

Ibrahim R (2013) Beginning Readers in Arabic and the Distance between Literary and Spoken Arabic . Creative Education, 4, 5, 307-314

Joseph, L. (2007). Best practices in planning interventions for students with reading problems. In A. Thomas \& F. Grimes (Eds). Best practices in school psychology V (pp. 803-817). Bethesda, MD: National Association of School Psychologists.

Kibby M. Y., Lee S. E., Dyer S. M. (2014). Reading performance is predicted by more than phonological processing. Front. Psychol. 5:960. 10.3389/fpsyg.2014.00960

Kibby, M. Y., \& Cohen, M. J. (2008). Memory Functioning in Children with Reading Disabilities and/or Attention-Deficit/Hyperactivity Disorder: A Clinical Investigation of Their Working Memory and Long-term Memory Functioning. Child Neuropsychology: A Journal on Normal and Abnormal Development in Childhood and Adolescence, 14(6), 525-546. http://doi.org/10.1080/09297040701821752

Kirby JR, Parrila R, Pfeiffer SL. Naming speed and phonological awareness as predictors of reading development. Journal of Educational Psychology. 2003;95(3):453-464.

Layes, S., Lalonde, R., \& Rebai, M. (2014). Reading speed and phonological awareness deficits among Arabic-speaking children with dyslexia. Dyslexia, 21(1), 80-95. doi:10.1002/dys.1491

Layes, S., Lalonde, R., Mecheri, S., Rebaï, M. (2015a). Phonological and cognitive reading related skills as predictors of word reading and reading comprehension among Arabic dyslexic children. Psychology, 6, 20-38.

Layes, S., Lalonde, R., Rebaï, M. (2015b). Effectiveness of a phonological awareness training for Arabic disabled reading children: insights on metalinguistic benefits. Bellaterra Journal of Teaching \& Learning Language \& Literature, 8(4), 24-42

Layes, S., Lalonde R., \& Rebaï, M. (2016). Study on morphological awareness and rapid automatized naming through word reading and comprehension in normal and disabled reading Arabic-speaking children. Reading \& Writing Quarterly, 33, 123-140.

Long, G. B., Fox, R. A., \& Jacewicz, E. (2016). Dyslexia Limits the Ability to Categorize Talker Dialect. Journal of Speech, Language, and Hearing Research : JSLHR, 59(5), 900-914. http://doi.org/10.1044/2016_JSLHR-S-15-0106

Lyon, G. R., Shaywitz, S. E., \& Shaywitz, B. A. (2003). Defining dyslexia, comorbidity, teachers' knowledge of language and reading: A definition of dyslexia. Annals of Dyslexia, 53, 1-14.

Majerus, S., \& Cowan, N. (2016). The nature of verbal short-term impairment in dyslexia: the Importance of serial order. Frontiers in Psychology, 7, 1522. http://doi.org/10.3389/fpsyg.2016.01522

Makhoul, B. , Olshtain, E. and Ibrahim, R. (2015) Fostering Phonological Awareness in a Computerized-Tutored Environment for Arabic Speaking First Graders At-Linguistic Risk. Open Journal of Modern Linguistics, 5, 120-134. doi: 10.4236/ojml.2015.52011.

Moll, K., Ramus, F., Bartling, J., Bruder, S., Kunze, S., Neuhoff, N.,et al. (2013). Cognitive mechanisms underlying reading and spelling development in five European orthographies. Learn. Instr. 29, 65-77. doi: 10.1016/j.learninstruc.2013.09.003

Nelson J. M., Lindstrom J. H., Lindstrom W., Denis D. (2012). The structure of phonological processing and its relationship to basic reading. Exceptionality 20 179-196.

Nelson J. M., Lindstrom J. H., Lindstrom W., Denis D. (2012). The structure of phonological processing and its relationship to basic reading. Exceptionality 20 179-196. 
Nithart C., Demont E., Metz-Lutz M. N., Majerus S., Poncelet M., Leybaert J. (2011). Early contribution of phonological awareness and later influence of phonological memory throughout reading acquisition. Journal of Research in Reading, 34, 346-363.

Powell, D., Stainthorp, R., Stuart, M., Garwood, H. \& Quinlan, P. (2007). An experimental comparison between rival theories of rapid automatized naming performance and its relationship to reading. Journal of Experimental Child Psychology, 98, 46-68.

Ramus, F., Rosen, S., Dakin, S. C., Day, B. L., Castellote, J. M., White, S., \& Frith, U. (2003). Theories of developmental dyslexia: Insights from a multiple case study of dyslexic adults. Brain, 126, 841-865.

Roman, A. A., Kirby, J. R., Parrila, R. K., Wade-Woolley, L., \& Deacon, S. H. (2009). Toward a comprehensive view of the skills involved in word reading in Grades 4, 6, and 8. Journal of Experimental Child Psychology, 102, 96-113. doi: 10.1016/j.jecp.2008.01.004

Saiegh-Haddad, E. (2004). The impact of phonemic and lexical distance on the phonological analysis of words and pseudowords in a diglossic context. Applied Psycholinguistics, 25, 495-512.

Saiegh-Haddad, E. (2005). Correlates of reading fluency in Arabic: Diglossic and orthographic factors. Reading and Writing: An Interdisciplinary Journal: An Interdisciplinary Journal, 18, 559-582.

Saiegh-Haddad, E. (2011). Phonological processing in diglossic Arabic: The role of linguistic distance. Perspectives on Arabic linguistics XXII, 269-280

Schneider W., Küspert P., Roth E., Visé M., Marx H. (1997). Short- and long-term effects of training phonological awareness in kindergarten: evidence from two German studies. J. Exp. Child Psychol. 66, 311-340. 10.1006/jecp.1997.2384

Schneider, W., Küspert, P., Roth, E., Vise, M., \& Marx, H. (1997). Short- and long-term effects of training phonological awareness in kindergarten: Evidence from two German studies. Journal of Experimental Child Psychology, 66, 311-340.

Seigneuric, A., Ehrlich, M.-F., Oakhill, J. V., \& Yuill, N. M. (2000). Working memory resources and children's reading comprehension. Reading and Writing, 13, 81-103.

Snowling, M. J. (2000). Dyslexia. Oxford, England: Blackwell

Snowling, M. J., \& Hulme, C. (2011) Evidence-based interventions for reading and language difficulties: Creating a virtuous circle, British Journal of Educational Psychology, 81, 1-23.

Stanovich, K. E. (1998). Refining the phonological core deficit model. Child Psychology and Psychiatry Review, 3, 17-21.

Thomson, J.M., Richardson, U. \& Goswami, U. (2005) Phonological similarity neighborhoods and children's short-term memory: Typical development and dyslexia, Memory \& Cognition 33: 1210. https://doi.org/10.3758/BF03193223

Torgesen, J. K., Alexander, A. W., Wagner, R. K., Rashotte, C. A., Voeller, K. K. S., \& Conway, T. (2001). Intensive remedial instruction for children with severe reading disabilities:

Immediate and long-term outcomes from two instructional approaches. Journal of Learning Disabilities, 34, 33-58.

Torgesen, J.K., Wagner, R.K., Rashotte, C.A., Lindamood, P., Rose, E., Conway, \& Garvan, C. (1999). Preventing reading failure in young children with phonological processing disabilities: Group and individual responses to instruction. Journal of Educational Psychology, 91, 579-593.

Torgesen, J.K.,Wagner, R.K., \& Rashotte, C.A. (1994). Longitudinal studies of phonological processing and reading. Journal of Learning Disabilities, 27, 276-286.

Van Kleeck, A., Gillam, R. B., \& Hoffman, L. M. (2006). Training in phonological awareness generalizes to phonological working memory: A preliminary investigation. The Journal of Speech-Language Pathology and Applied Behavior Analysis, 1, 228 - 243.

Vellutino F. R., Fletcher J. M., Snowling M. J., Scanlon D. M. (2004). Specific reading disability (dyslexia): what have we learned in the past four decades? J. Child Psychol. and Psychiatry 45 2-40 10.1046/j.0021-9630.2003.00305.x 
Vellutino, F. R., \& Fletcher, J. M. (2007). Developmental dyslexia. In M. J. Snowling \& C. Hulme (Eds.), The science of reading: A handbook (pp. 362-378). Oxford, England: Blackwell.

Vellutino, F., Scanlon, D. 1987 Phonological coding, phonological awareness, and reading ability: Evidence from a longitudinal and experimental studyMerrill-Palmer Quarterly33321363

Von Bastian CC1, Oberauer K. Effects and mechanisms of working memory training: a review. Psychol Res. 2014 Nov;78(6):803-20. doi: 10.1007/s00426-013-0524-6. Epub 2013 Nov 10.

Wagner R. K., Torgesen J. K., Rashotte C. A. (1994). Development of reading-related phonological processing abilities: New evidence of bidirectional causality from a latent variable longitudinal study. Developmental Psychology, 30, 73-87.

Wagner, R. K., Torgesen, J. K., Laughon, P., Simmons, K., \& Rashotte, C. A. (1993). The development of young readers' phonological processing abilities. Journal of Educational Psychology, 85, 1-20.

Wagner, R.K. \& Torgesen, J.K.. (1987). The Nature of Phonological Processing and Its Causal Role in the Acquisition of Reading Skills. Psychological Bulletin. 101. 192-212.

Wagner, R.K., Torgesen, J.K., Rashotte, C.A., Hecht, S.A., Barker, T.A., Burgess, S.R., Donahue, J., \& Garon,T. (1997). Changing causal relations between phonological processing abilities and word-level reading as children develop from beginning to fluent readers: A five-year longitudinal study. Developmental Psychology, 33, 468- 479. 468-79. 10.1037/00121649.33.3.468

Wang L-C (2017). Effects of Phonological Training on the Reading and Reading-Related Abilities of Hong Kong Children with Dyslexia Front. Psychol. https://doi.org/10.3389/fpsyg.2017.01904

Wise, B. W., Ring, J., \& Olson, R. K. (1999). Training phonological awareness with and without explicit attention to articulation. Journal of Experimental Child Psychology, 72, 271-304.

Wolf, M., Bowers, P.G. (1999). The double-deficit hypothesis for the developmental dyslexias Journal of Educational Psychology, 91 (3), 415-438

Ziegler, J. C., \& Goswami, U. (2005). Reading acquisition, developmental dyslexia, and skilled reading across languages: A psycholinguistic grain size theory. Psychological Bulletin, 131, 3-29. doi:10.1037/0033-2909.131.1.3

Table 1. Comparison between experimental and control groups in pre-training measures

\begin{tabular}{llllllll}
\hline \multirow{2}{*}{ Measures } & \multicolumn{2}{l}{ Experimental group } & \multicolumn{2}{l}{ Control group } & \multirow{2}{*}{$\mathrm{t}=(2.02)$} & \multirow{2}{*}{ Sig. } \\
\cline { 2 - 6 } Age & Mean & SD & Mean & SD & & \\
Raven & 122.90 & 11.40 & 124.65 & 10.08 & 0.51 & $>.05$ \\
Freq. word & 10.85 & 1.08 & 10.70 & .80 & 0.49 & $>.05$ \\
Infreq. word & 15.40 & 2.08 & 14.90 & 1.94 & 0.78 & $>.05$ \\
Pseudo word & 13.15 & 3.23 & 12.10 & 3.22 & 1.02 & $>.05$ \\
Total word reading & 5.05 & 1.73 & 6.00 & 2.24 & -1.47 & $>.05$ \\
Total reading & 28.55 & 3.56 & 27.00 & 2.95 & 1.49 & $>.05$ \\
PA & 33.60 & 3.63 & 33.00 & 3.58 & 0.52 & $>.05$ \\
VSTM & 6.55 & 1.572 & 7.15 & 1.182 & -1.36 & $>.05$ \\
RAN & 7.95 & 1.669 & 8.65 & .587 & -1.76 & $>.05$ \\
\hline
\end{tabular}




\begin{tabular}{|c|c|c|c|c|c|c|c|c|}
\hline \multirow{2}{*}{$\begin{array}{l}\text { Measures } \\
\text { Frequent word }\end{array}$} & \multirow{2}{*}{$\begin{array}{l}\text { Mean } \\
-4.80\end{array}$} & \multicolumn{2}{|c|}{$\mathrm{SD}$} & \multirow{2}{*}{$\begin{array}{l}\text { t-test value } \\
-6.46\end{array}$} & \multirow{2}{*}{$\begin{array}{l}\text { Sig. } \\
<.000\end{array}$} & \multicolumn{2}{|c|}{ Cohen's $d$} & \\
\hline & & & & & & -1.8 & & \\
\hline Infrequent word & -2.55 & \multicolumn{2}{|c|}{4.28} & -2.66 & $<.01$ & \multicolumn{2}{|l|}{-.63} & \\
\hline Pseudo word & -2.40 & \multicolumn{2}{|c|}{2.28} & -4.70 & $<.000$ & \multicolumn{2}{|c|}{-1.26} & Com \\
\hline Total word reading & -7.35 & \multicolumn{2}{|c|}{4.83} & -6.79 & $<.000$ & \multicolumn{2}{|c|}{1.89} & paris \\
\hline Total reading & -9.75 & \multicolumn{2}{|c|}{5.48} & -7.94 & $<.000$ & \multicolumn{2}{|c|}{2.21} & \\
\hline PA & -2.05 & \multicolumn{2}{|c|}{1.31} & -6.96 & $<.000$ & \multicolumn{2}{|c|}{-1.89} & een \\
\hline \multirow[b]{2}{*}{ Measures } & \multicolumn{2}{|c|}{ Experimental group } & \multicolumn{2}{|c|}{ Control group } & & \multirow{2}{*}{ Sig. } & \multirow{2}{*}{\multicolumn{2}{|c|}{ Cohen's $d$}} \\
\hline & Mean & SD & Mean & SD & $.02)$ & & & \\
\hline Freq. word & 20.20 & 2.93 & 15.40 & 2.52 & 5.55 & .000 & 1.7 & 75 \\
\hline Infreq. word & 15.70 & 2.05 & 11.65 & 1.59 & 6.95 & .000 & 2.2 & 20 \\
\hline Pseudo word & 7.45 & 1.27 & 6.70 & .92 & 2.12 & .04 & 0.6 & 67 \\
\hline Total word reading & 35.90 & 3.91 & 27.05 & 3.03 & 7.98 & .000 & 2.5 & 53 \\
\hline Total reading & 43.35 & 4.56 & 33.75 & 2.63 & 8.14 & .000 & 2.5 & 57 \\
\hline PA & 8.60 & 1.35 & 7.75 & .78 & 2.43 & .02 & 0.7 & 77 \\
\hline VSTM & 9.70 & .73 & 8.85 & .87 & 3.33 & .002 & 1.0 & 05 \\
\hline RAN & 20.70 & 2.02 & 22.50 & 2,09 & -2.76 & .009 & 0.8 & 87 \\
\hline
\end{tabular}

Table 3. Comparison between pre-and post-training measures for the experimental group 


\begin{tabular}{llllll} 
VSTM & -1.75 & 1.77 & -4.41 & $<.000$ & -1.26 \\
RAN & 3.25 & 2.84 & 5.10 & $<.000$ & 1.58 \\
\hline
\end{tabular}

Table 4. Comparison between pre and post-training measures for the control group

\begin{tabular}{lcccc}
\hline Measures & Mean & SD & t-test value & Sig. \\
\hline Frequent word & -.50 & 2.16 & -1.03 & $>.05$ \\
Infrequent word & .45 & 4.13 & .48 & $>.05$ \\
Pseudo word & -.70 & 2.81 & -1.11 & $>.05$ \\
Total word reading & -.05 & 4.54 & -.04 & $>.05$ \\
Total reading & -.75 & 4.75 & -.70 & $>.05$ \\
PA & -.60 & 1.53 & -1.74 & $>.05$ \\
VSTM & -.20 & .52 & -1.71 & $>.05$ \\
RAN & .65 & 1.72 & 1.08 & $>.05$ \\
\hline
\end{tabular}




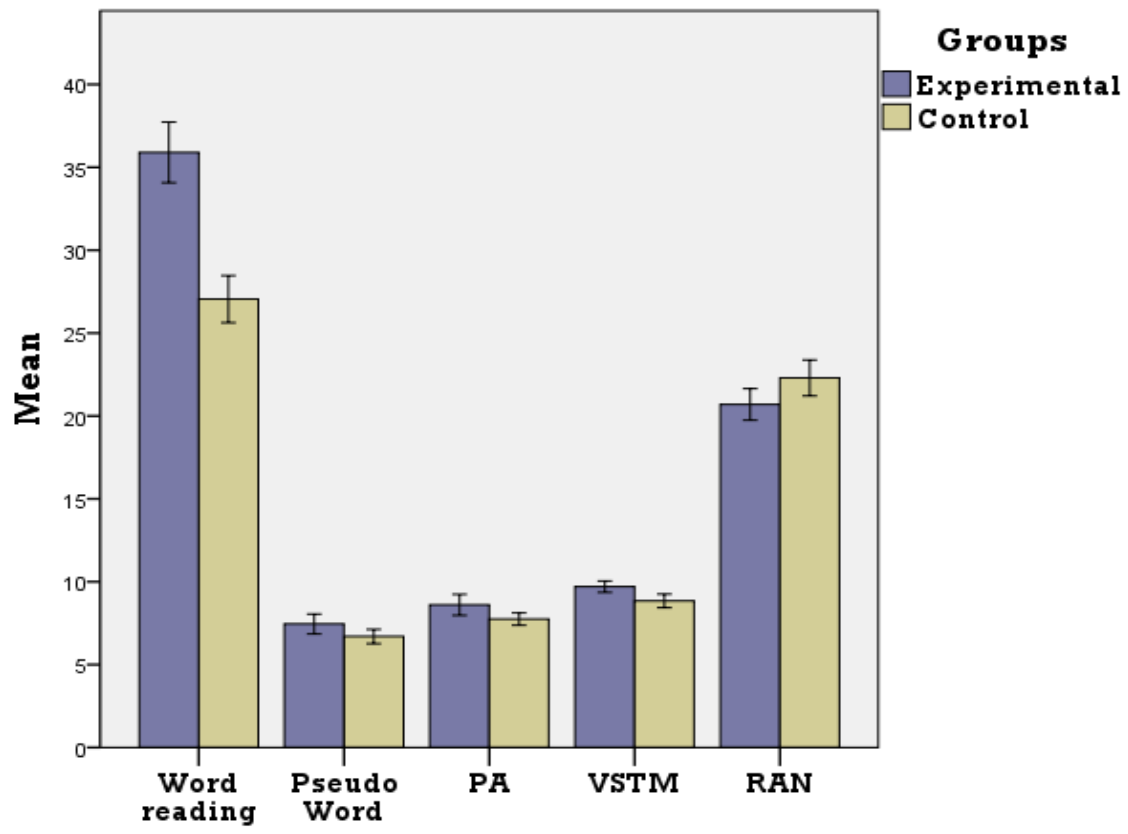

Figure 1. Differences between training and control groups in post training measures 